\title{
Experimental and numerical investigation on flexural bond strength behavior of corroded NBS RC beam
}

\author{
Akshatha Shetty $^{1} \cdot$ Katta Venkataramana $^{2}$ - K. S. Babu Narayan ${ }^{2}$
}

Received: 31 January 2014/ Accepted: 16 April 2015/Published online: 20 May 2015

(c) The Author(s) 2015. This article is published with open access at Springerlink.com

\begin{abstract}
Corrosion of reinforcing steel is the most detrimental effect endangering the structural performance. Present investigation has been taken up to study the detrimental effect of corrosion on bond behavior. Experimental and numerical investigation has been carried out for four different levels of corrosion-2.5, 5, 7.5 and $10 \%$. Loss in mass of reinforcement bar has been taken as the basis to fix corrosion levels. Accelerated corrosion technique has been adopted to control corrosion rate by regulating current over predetermined durations. NBS beams have been investigated for performance. Concrete grade M30 and steel Fe-415 have been used. From the experimental investigation, it has been observed that bond strength degradation of $2.6 \%$ at slip initiation and $2.1 \%$ at end of slip have been observed for every percentage increases in corrosion level. Numerical investigation with concrete is modeled as solid 65 element and reinforcement modeled as Link 8 elements. ANSYS has yielded 3 and $2.4 \%$ bond strength degradation values at initiation and end of slip per percentage increase in corrosion levels.
\end{abstract}

Keywords Bond stress · Corrosion · Load - Slip · Strain · Reinforcement · Numerical model

\section{List of symbols \\ $\rho \quad$ Degree of corrosion \\ $T$ Time in seconds}

Akshatha Shetty

akshathashetty16@gmail.com

1 Department of Civil Engineering, NMAMIT, Nitte, Udupi, Karnataka, India

2 Department of Civil Engineering, National Institute of Technology Karnataka, Surathkal, India
$W_{\mathrm{i}} \quad 20,000 \mathrm{~g}$ (initial weight of steel)

$F \quad 96487$ A-s (Faradays constant)

$W \quad 27.925 \mathrm{~g}$ (equivalent weight of steel)

$i_{\text {app }}$ Applied current (A)

$\tau_{\text {bd }} \quad$ Average bond stress $\left(\mathrm{N} / \mathrm{mm}^{2}\right)$

$\phi \quad$ Initial diameter $(25 \mathrm{~mm})$

$\phi_{1} \quad$ Reduced diameter $(\mathrm{mm})$ values

$p \quad$ Weight loss in percentage

$l_{\mathrm{d}} \quad$ Embedment length of the bar $(747 \mathrm{~mm})$ from the test setup

$f_{\mathrm{s}} \quad$ Bar stress

' $s$ ' Slip value $(\mathrm{mm})$

' $c$ ' Thickness of cover layer ( $\mathrm{mm})$

' $d$ ' Diameter of reinforcement (mm)

$f_{\mathrm{t}, \mathrm{s}} \quad$ Concrete's splitting tensile strength $\left(\mathrm{N} / \mathrm{mm}^{2}\right)$

$\eta \quad$ Corrosion rate

$\beta \quad$ Reduction factor

$L \quad$ Bond force

\section{Introduction}

Tremendous increase in demand for resources and acute shortage of the same is like a double-edged sword. Codes and construction practices are emphasizing durability to cope with the situation. The fact embedded steel corrodes faster than exposed has made researchers revisit the area to refine and redefine analysis and design.

Corrosion is defined as the destruction or deterioration of a material because of its reaction with environment (Fontana 2005). Chloride ingress into the concrete is a major cause of steel corrosion. Presence of chloride ions at the rebar level leads to the breakdown of passive firm thin 
film layer and consequently initiates the corrosion (Pradhan and Bhattacharjee 2009). Rust produced as a result of corrosion increases its volume 2-6 times than that of original steel; it causes increase in volume of tensile stresses in concrete (Bhaskar et al. 2010).

Corrosion of reinforcement is a prime concern as stability, strength, safety, serviceability, durability and economy of RC structures are severely affected. One of the most important prerequisites of reinforced concrete construction is adequate bond between the reinforcement and the concrete.

\section{Significance of bond strength}

Reinforced steel bar can receive its external loads only from the surrounding concrete, because external loads are very rarely applied directly on it. 'Slip' is the differential displacement between steel and concrete. Composite action between concrete and reinforcing steel cannot occur without bond (Amleh 2000).

Bond resistance of reinforcing bars embedded in concrete depends primarily on frictional resistance and mechanical interlock. Chemical adhesion provides withholding property between steel and concrete. Frictional bond provides initial resistance against loading and further loading mobilizes the mechanical interlock between the concrete and bar ribs. Mechanical interlocks lead to inclined bearing forces which in turn lead to transverse tensile stresses and internal inclined splitting (bond) cracks along reinforcing bars. These cracks are commonly referred as Goto cracks (Goto 1971).

This work is an attempt to understand affect of corrosion on bond characteristic. The study envisaged to quantify loss in bond strength due to corrosion.

\section{Experimental investigation}

Details of experiments, mix design and of test setup used for the study are explained below.

\section{Mix design details}

According to the recommendation of IS 456-2000 code, minimum concrete grade to be adopted in coastal environment is M30 and maximum water cement ratio is 0.45 . Hence, target strength of $30 \mathrm{~N} / \mathrm{mm}^{2}$ and slump range of 50-60 $\mathrm{mm}$ are selected for the present study. Mix design calculations are made as per IS 10262-2009. Test results of materials are used in the calculation of determination of mix proportions. After several trials, the mix proportion of 1:1.77:2.87 is achieved. An addition of $2 \mathrm{ml} / \mathrm{kg}$ of commercially available chemical admixture is used to get the desired level of slump. Compressive strength of control cube is obtained as $34.44 \mathrm{~N} / \mathrm{mm}^{2}$.

\section{Preparation of test specimens}

For the present study, National Bureau of Standard (NBS) beam specimens of size $2.44 \mathrm{~m} \times 0.457 \mathrm{~m} \times 0.203 \mathrm{~m}$ [Fig. 1 (Paul 1978)] are used. After curing of beam specimens for 28 days, to accelerate the corrosion process in beam specimens impressed current technique is used. Specimens are partially immersed in a $5 \% \mathrm{NaCl}$ solution for an duration of 8 days. Current required to achieve different corrosion levels can be obtained using Faraday's law (Eq. 1) (Ahmad 2009). Based on the calculation amount of 2.5-10 A current at the variation of $2.5 \mathrm{~A}$ are applied to obtain the required corrosion level, i.e., $2.5-10 \%$ at the variation of $2.5 \%$, respectively.
Fig. 1 Reinforcement details of NBS beam specimen
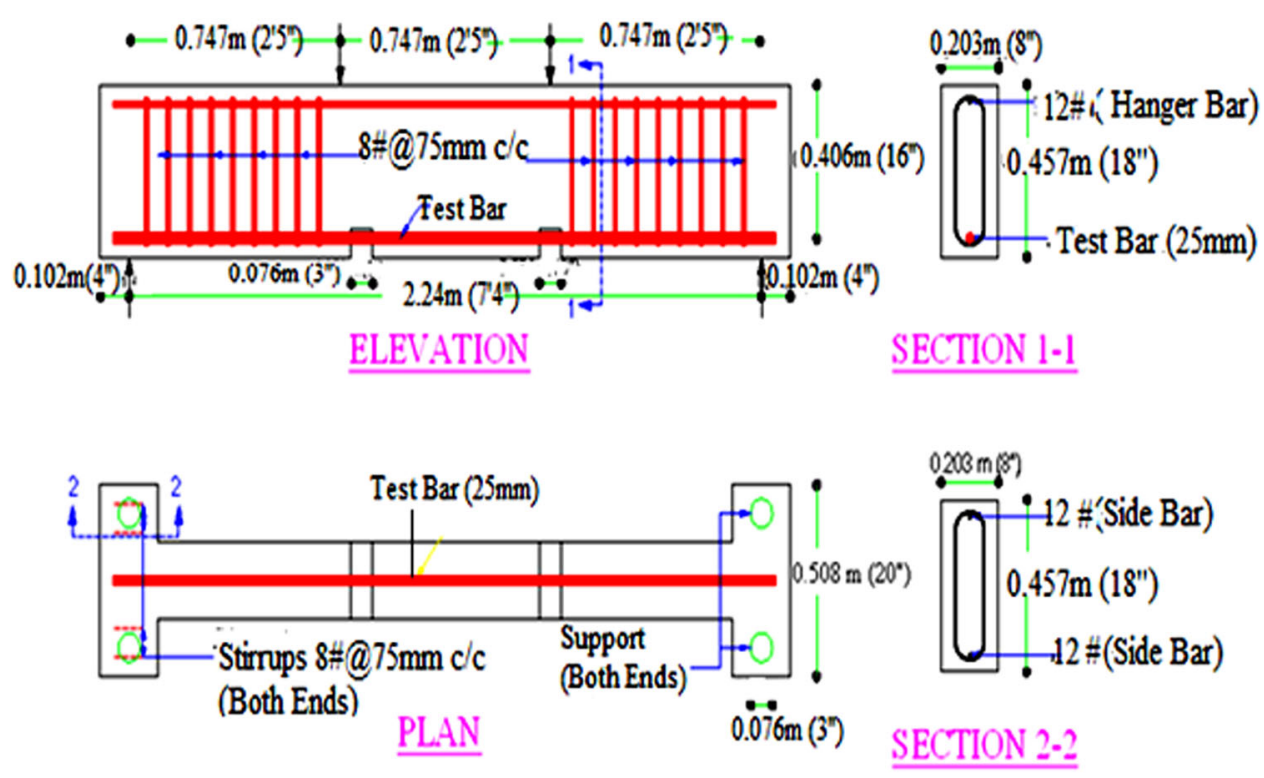


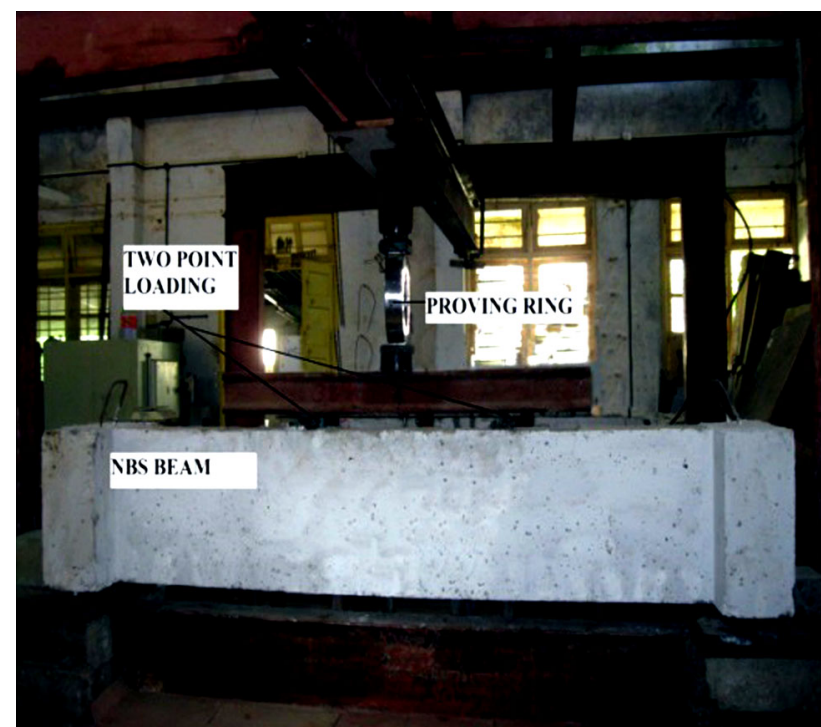

Fig. 2 Test setup of NBS beam specimen

Monitoring of corrosion process is done by applied corrosion monitoring (ACM) instrument.

$i_{\text {app }}=\frac{\left(\rho \times w_{i} \times F\right)}{100 \times \pi \times D \times L \times W \times T}$,

where $\rho$ is the degree of corrosion, $T$ is the time in seconds, $W_{\mathrm{i}}$ is the initial weight of steel $(=20,000 \mathrm{~g}$ present study), $F$ is equal to $96487 \mathrm{~A}-\mathrm{s}, W$ is the equivalent weight of steel (=27.925 g), $i_{\text {app }}$ is the applied current (A).

\section{Test setup used for flexural bond study}

Test setup used for the present study is shown in Fig. 2. Beam specimens are tested under two-point loading condition. The load is applied at $15 \mathrm{kN}$ increments. Proving ring of 50 ton capacity is used to note the applied load.

Strain value recordings have been done using demec gauges at every load interval. Positions of demec targets have been shown in Fig. 3.

\section{Determination of bond stress}

Average bond stress values are obtained from Eq. (2).

$\tau_{\mathrm{bd}}=\frac{\phi_{1} \times f_{s}}{4 \times l_{d}}$,

where the diameter of bar is

$\phi_{1}=\phi \sqrt{\left(1-\frac{p}{100}\right)} ;$

$\tau_{\text {bd }}$ is the average bond stress $\left(\mathrm{N} / \mathrm{mm}^{2}\right) ; \phi$ is the initial diameter $(25 \mathrm{~mm}) ; \phi_{1}$ are the reduced diameter $(\mathrm{mm})$ values presented in Tables 1 and 2; $p$ is the weight loss in

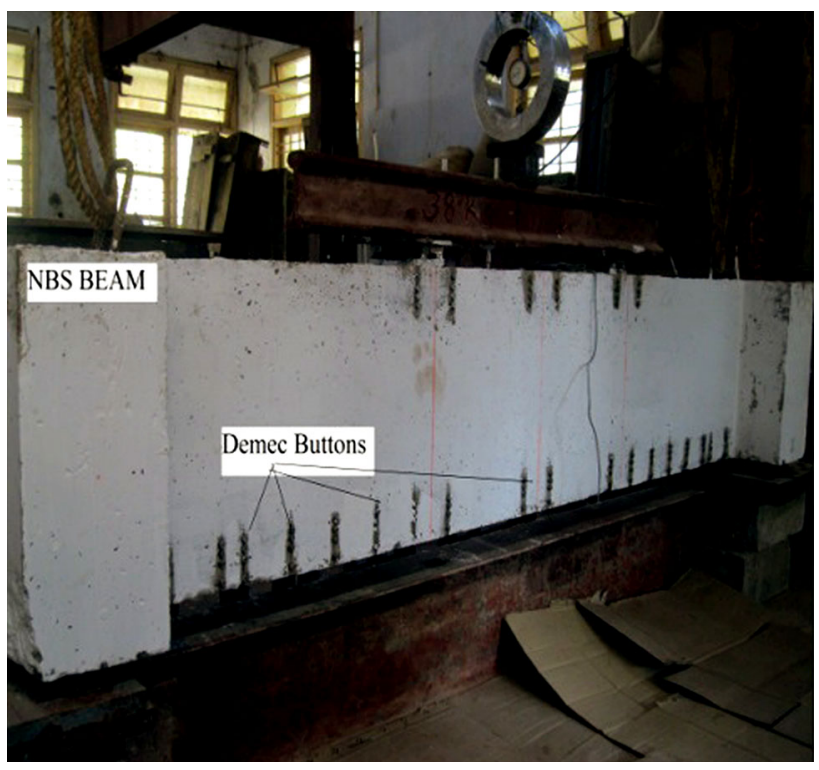

Fig. 3 Demec buttons were at $100 \mathrm{mmc} / \mathrm{c}$

percentage; $l_{\mathrm{d}}$ is the embedment length of the bar $(747 \mathrm{~mm})$ from the test setup; $f_{\mathrm{s}}$ are the steel stress values obtained for initiation and end strain values at slip region for different corrosion levels from stress corresponding to strains at that load level (Fig. 4).

To overcome the problems of material cost and long time duration in real-time study, FEM (Numerical modeling) analysis is carried out on NBS beams based on the experimental study.

\section{Numerical investigation}

To model NBS beam specimen of size $2.44 \mathrm{~m} \times 0.203 \mathrm{~m} \times$ $0.457 \mathrm{~m}$ by FEM, a commercial ANSYS software package is used. Graphical user interface in ANSYS provides different element types, which suits the problem on hand. Hence this software is preferred for the present study.

\section{Element types}

To model concrete, Solid 65 element is used. The element has eight nodes with three degrees of freedom at each node translation in the nodal $x, y$ and $z$ direction. To model steel reinforcement, Link 8 element is used. Link 8 element has two nodes with three degrees of freedom at each node translation in the nodal $x, y$ and $z$ direction.

\section{Real constants}

Real constant Set 1 is defined for the Solid 65 element. In the present study, the beam is modeled using discrete reinforcement. Therefore, a value of zero is entered for all real constants, which turn the smeared reinforcement 
Table 1 Bar force, reduced diameter and bond stress performance for different levels of corrosion in experimental beam specimens

\begin{tabular}{|c|c|c|c|c|c|c|c|c|}
\hline \multirow{3}{*}{$\begin{array}{l}\text { Corrosion } \\
\text { levels }(\%)\end{array}$} & \multicolumn{8}{|c|}{ Bar force and bond stress values for initial and final slip point (experimental results) } \\
\hline & \multicolumn{4}{|c|}{ Initiation of slip value } & \multicolumn{4}{|c|}{ End of slip value } \\
\hline & Microstrain & $\begin{array}{l}f_{\mathrm{s}} \text {-stress } \\
\text { in bar }\end{array}$ & $\begin{array}{l}\text { Reduced } \\
\text { diameter }(\mathrm{mm})\end{array}$ & $\begin{array}{l}\text { Bond stress } \\
\left(\mathrm{N} / \mathrm{mm}^{2}\right)\end{array}$ & Microstrain & $\begin{array}{l}f_{\mathrm{S}} \text {-stress } \\
\text { in bar }\end{array}$ & $\begin{array}{l}\text { Reduced } \\
\text { diameter }(\mathrm{mm})\end{array}$ & $\begin{array}{l}\text { Bond stress } \\
\left(\mathrm{N} / \mathrm{mm}^{2}\right)\end{array}$ \\
\hline 0 & 700 & 199.21 & 25.00 & 1.67 & 1330 & 367.96 & 25.00 & 3.08 \\
\hline 2.5 & 660 & 188.85 & 24.69 & 1.56 & 1275 & 353.58 & 24.69 & 2.92 \\
\hline 5 & 600 & 177.59 & 24.37 & 1.45 & 1210 & 337.08 & 24.37 & 2.75 \\
\hline 7.5 & 560 & 163.25 & 24.04 & 1.31 & 1110 & 310.00 & 24.04 & 2.49 \\
\hline 10 & 505 & 148.13 & 23.72 & 1.18 & 1050 & 293.93 & 23.72 & 2.33 \\
\hline
\end{tabular}

Table 2 Bar force, reduced diameter and bond stress performance for different levels of corrosion in numerical model beam specimens

\begin{tabular}{|c|c|c|c|c|c|c|c|c|}
\hline \multirow{3}{*}{$\begin{array}{l}\text { Corrosion } \\
\text { levels }(\%)\end{array}$} & \multicolumn{8}{|c|}{ Bar force and bond stress values for initial and final flat end regions (ANSYS) } \\
\hline & \multicolumn{4}{|c|}{ ANSYS (initiation of slip value) } & \multicolumn{4}{|c|}{ ANSYS (end of slip value) } \\
\hline & Microstrain & $\begin{array}{l}f_{\mathrm{s}} \text {-stress } \\
\text { in bar }\end{array}$ & $\begin{array}{l}\text { Reduced bar } \\
\text { diameter }(\mathrm{mm})\end{array}$ & $\begin{array}{l}\text { Bond stress } \\
\left(\mathrm{N} / \mathrm{mm}^{2}\right)\end{array}$ & Microstrain & $\begin{array}{l}f_{\mathrm{S}} \text {-stress } \\
\text { in bar }\end{array}$ & $\begin{array}{l}\text { Reduced } \\
\text { diameter (mm) }\end{array}$ & $\begin{array}{l}\text { Bond stress } \\
\left(\mathrm{N} / \mathrm{mm}^{2}\right)\end{array}$ \\
\hline 0 & 660 & 188.91 & 25.00 & 1.58 & 1290 & 360.00 & 25.00 & 3.01 \\
\hline 2.5 & 610 & 176.20 & 24.69 & 1.46 & 1240 & 344.70 & 24.69 & 2.85 \\
\hline 5 & 560 & 163.31 & 24.37 & 1.33 & 1150 & 321.00 & 24.37 & 2.62 \\
\hline 7.5 & 510 & 149.50 & 24.04 & 1.20 & 1070 & 299.00 & 24.04 & 2.41 \\
\hline 10 & 470 & 138.50 & 23.72 & 1.10 & 1010 & 283.80 & 23.72 & 2.25 \\
\hline
\end{tabular}

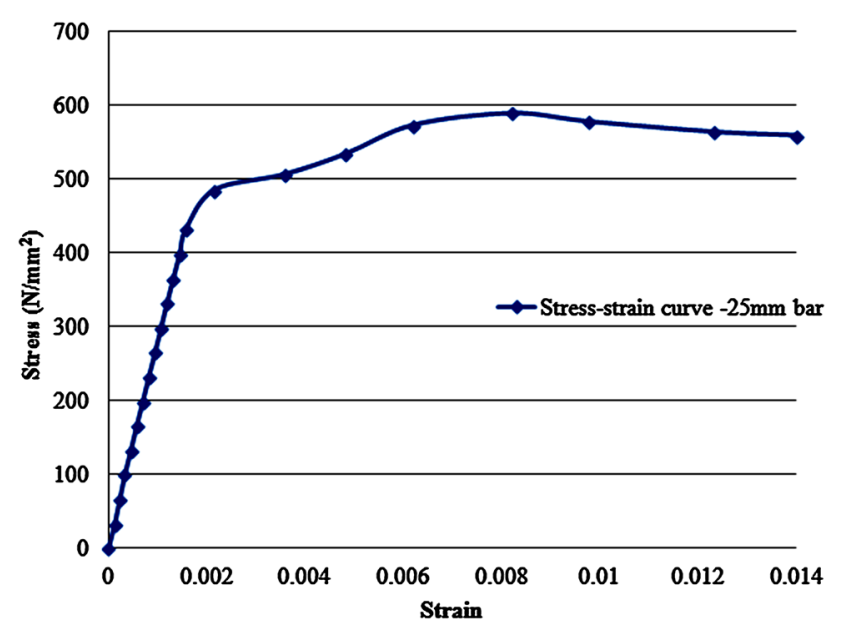

Fig. 4 Stress-strain curve for $25 \mathrm{~mm}$ diameter TMT Fe-415 reinforcing steel bar

capability of the Solid 65 element off. Real constant Sets 2, 3 and 4 are defined for the Link 8 element. Real constant values of Link 8 (cross-sectional area and initial strain) are entered as follows,

- Set 2: cross-sectional area of $25 \mathrm{~mm}$ bar: $490.87 \mathrm{~mm}^{2}$

- Set 3: cross-sectional area of $12 \mathrm{~mm}$ bar: $113.10 \mathrm{~mm}^{2}$

- Set 4: cross-sectional area of $8 \mathrm{~mm}$ two-legged stirrups: $50.27 \mathrm{~mm}^{2}$
A value of zero is entered for the initial strain because it is assumed that there is no initial stress in the reinforcement.

For different levels of corrosion $(2.5,5,7.5$ and $10 \%)$, reduced bar diameter can be obtained from the Eq. (3).

Real constant Set 4 is defined for the Combin39 element; to simulate the bonding behavior, nonlinear spring element is adopted at the bar concrete interface for simulating its bond-slip relationship. Combin39 elements' nonlinearity can be defined by giving load displacement relationship as input.

The relationship between local bond stress and slip at the bar concrete interface along the longitudinal direction is given below (Xiaoming and Hongqiang 2012):

$$
\begin{aligned}
\tau(s)= & \left(61.5 s-693 s^{2}+3.14 \times 10^{3} \times s^{3}-0.478 \times 10^{4} \times s^{4}\right) \\
& \times f_{\mathrm{t}, \mathrm{s}} \times \sqrt{c / d},
\end{aligned}
$$

in which ' $s$ ' is the slip value $(\mathrm{mm})$, ' $c$ ' the thickness of cover layer (mm), ' $d$ ' the diameter of reinforcement $(\mathrm{mm})$, $f_{\mathrm{t}, \mathrm{s}}$ the concrete's splitting tensile strength $\left(\mathrm{N} / \mathrm{mm}^{2}\right)$, where

$f_{\mathrm{t}, \mathrm{s}}=0.19 \times f_{\mathrm{ck}}^{0.75}$.

In the FE model of the RC beam, the relationship between the bond force ' $L$ ' and slip value ' $s$ ' can be calculated as follows: 


$$
L(s)=\tau(s) \pi d l
$$

where $d$ is the diameter of a bar ( $\mathrm{mm})$ and $l$ the distance between two adjacent spring elements (mm). From Eqs. (4) and (6), the load displacement relationship (L-D) of the spring element longitudinal direction can be obtained.

When the corrosion rate is $\eta$, the reduction factor $\beta$ of the bond strength at the corroded bar-concrete interface can be calculated as follows (Xu 2003):

$\beta=\left\{1+0.5625 \eta-0.3357 \eta^{2}+0.055625 \eta^{3}-0.003 \eta^{4} \eta \leq 7 \%\right\}$

$\beta=\left\{2.0786 \eta^{-1.0369} \eta>7 \%\right\}$.

Substituting Eqs. (7) into (6), the relationship between the bond force ' $L$ ' and slip value ' $s$ ' after corrosion can be obtained as:

$L(s)=\beta \times \tau(s) \times \pi d l$

Thus, the L-D curves of the spring element along the longitudinal direction under different corrosion rates are presented in Fig. 5.

\section{Modeling}

Input values for numerical model of beam are given as per the experimental study. In the present study, elastic modulus of concrete (Solid 65) element is $29,342.8 \mathrm{~N} / \mathrm{mm}^{2}$ and Poisson ratio is 0.2 . Simplified compressive uniaxial stress strain curve for concrete is shown in Fig. 6. Uniaxial tensile strength is $4.1 \mathrm{~N} / \mathrm{mm}^{2}$, crack opening shear transfer coefficient is 0.3 and crack closing shear transfer coefficient is 0.95 . To obtain good results, hexahedric mesh is used for the modeling (ANSYS 2012). Full beam was modeled using 56 nodes in the $x$ direction (i.e., longitudinal direction) placed with a spacing of $39.6 \mathrm{~mm}$ between successive nodes in the loading places, $18 \mathrm{~mm}$ at the support point and $75 \mathrm{~mm}$ at the center. In $Y$ direction (i.e., transverse direction), 9 nodes were placed at $50 \mathrm{~mm}$

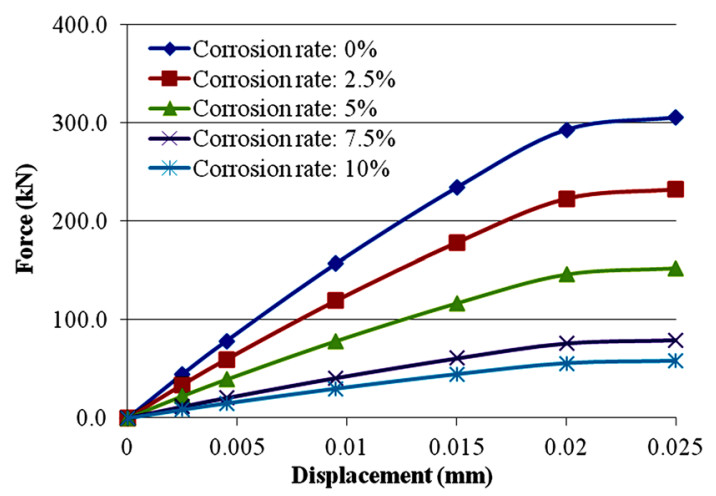

Fig. 5 Load-displacement relationship of the spring element (Combin39) along the longitudinal direction

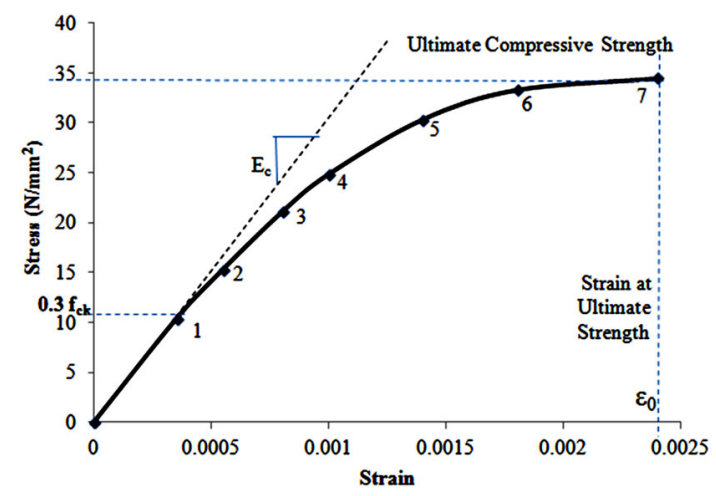

Fig. 6 Simplified compressive uniaxial stress-strain curve for concrete

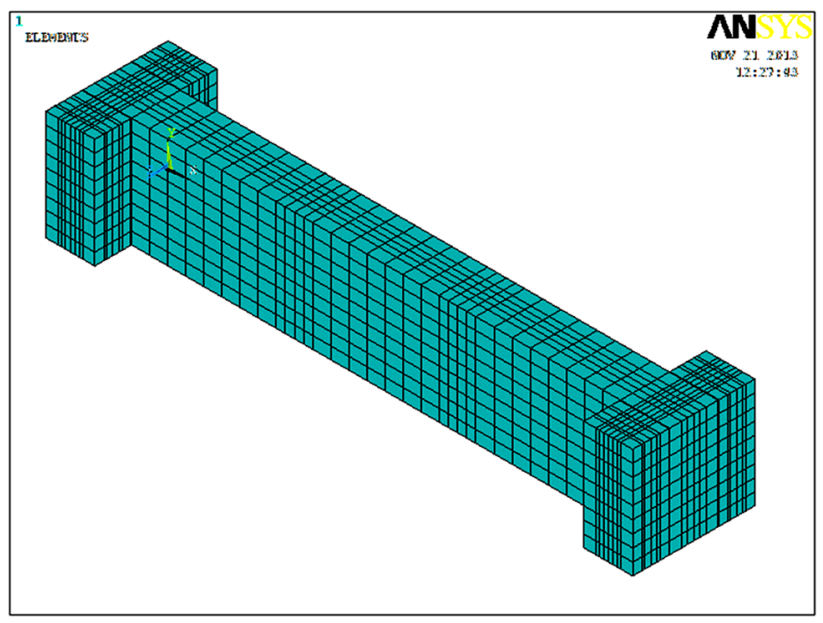

Fig. 7 Concrete element of NBS beam model

between two successive nodes. In $Z$ direction, the nodes were placed at $32 \mathrm{~mm}$ distance. Concrete element model of beam is shown in Fig. 7.

Elastic modulus of Link 8 element is $2 \times 10^{5} \mathrm{~N} / \mathrm{mm}^{2}$ and its Poisson ratio is 0.3 . The yield strength of the main bar is $485 \mathrm{~N} / \mathrm{mm}^{2}$. The bar model is shown in Fig. 8 .

In case of main reinforcement bar modeling $(25 \mathrm{~mm}$ diameter), separate nodes at same location (Link 8 elements and Solid 65 elements) are connected with Combin39 element to simulate the bond slip behavior. A view of reinforcements inside concrete volume is shown in Fig. 9. Other reinforcement is modeled through discrete reinforcement modeling method (concrete and steel nodes merged into single entities).

\section{Loads and boundary conditions}

To get the unique solution constraining the models using displacement boundary conditions, same ways as that of experimental beam boundary conditions are very much necessary. 


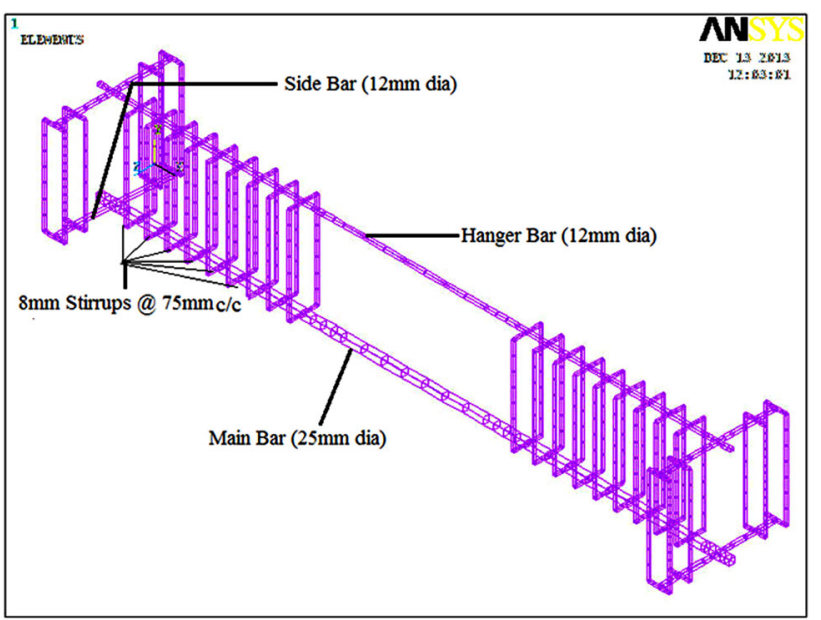

Fig. 8 Reinforcement element model of NBS beam

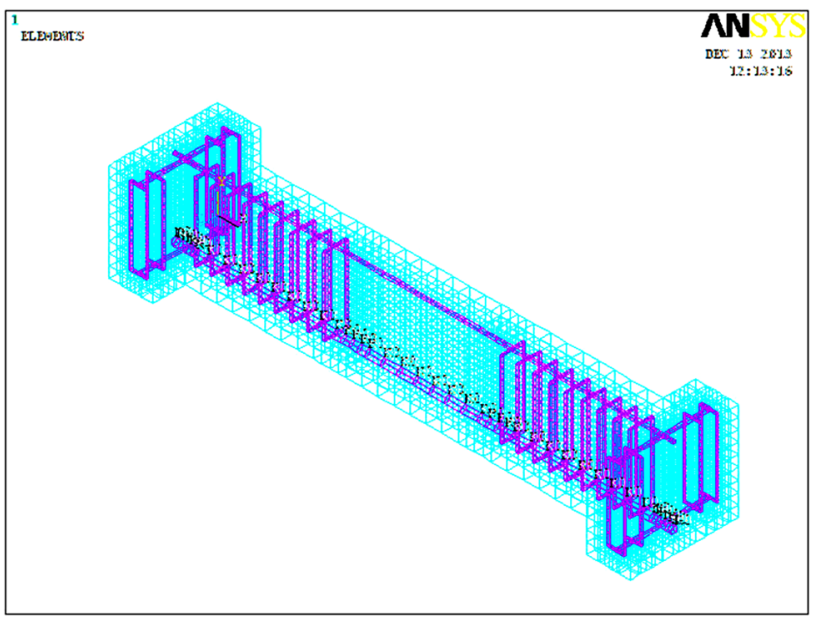

Fig. 9 View of Reinforcements inside concrete

Supports are modeled such a way that a roller is created. A single line of nodes on the beam are given constraint in the UY and UZ (translation in $Y$ and $Z$ ) directions, applied as constant values of 0 . By doing this, the beam will be allowed to rotate at the support. Loading and support conditions are shown in Fig. 10a, b.

\section{Analysis process for the finite element model}

The FE analysis of the model is considered to examine the results of different corrosion levels. Static analysis type is utilized in the present investigation since the finite element model for this analysis is a NBS beam under transverse loading.

The Newton-Raphson method of analysis is used to compute the nonlinear response. The loads are applied at $15 \mathrm{kN}$ increment up to failure. After each load increment, the restart option is used to go to the next step after convergence.
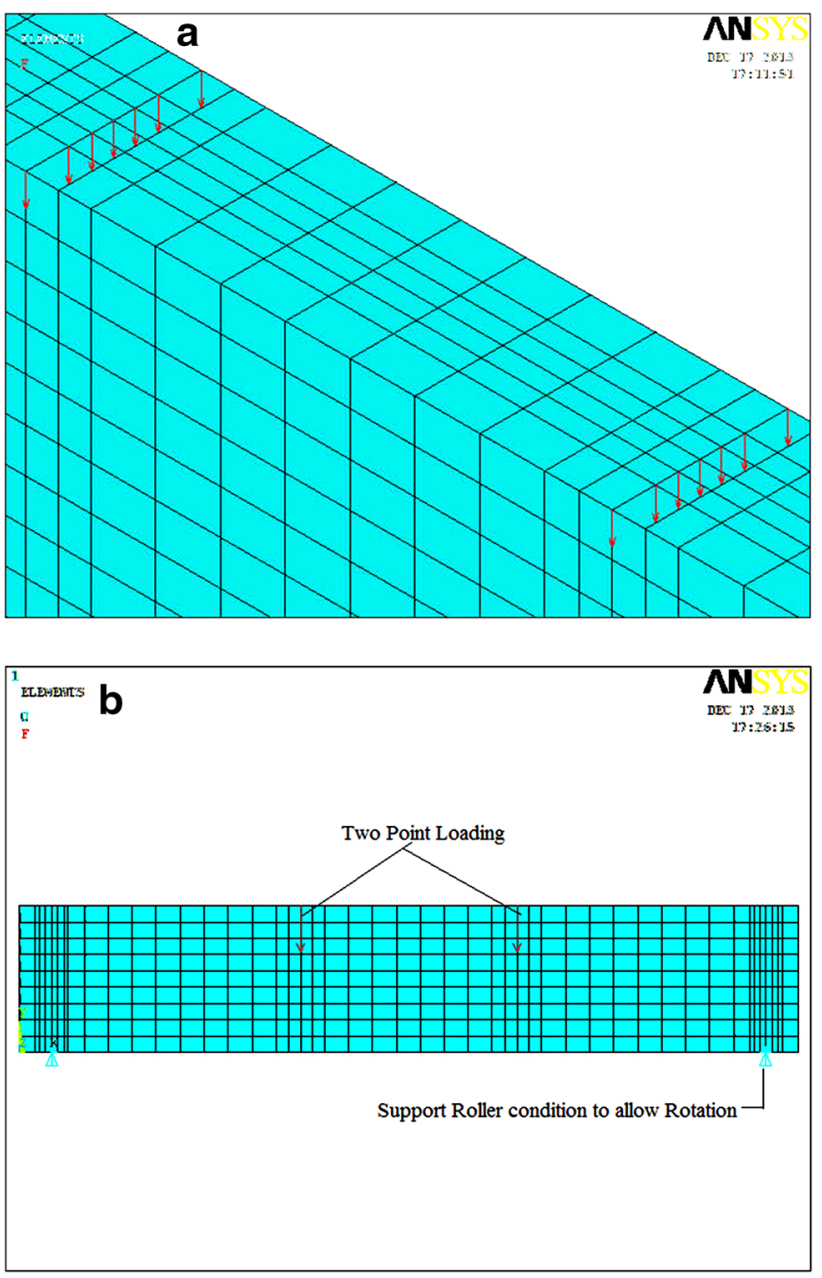

Fig. 10 a Loading condition for NBS beam specimen. b Support and loading conditions of NBS beam specimen

Strain values are noted from the numerical results at the load points and bond stress values can be obtained from Eq. (2).

\section{Results and discussion}

\section{Ultimate load-carrying capacity and bond stress of NBS beams}

Effect of corrosion on ultimate load-carrying capacity is shown in Fig. 11. As the degree of corrosion level increases, load-carrying capacity decreases (Fig. 11). It is also observed that for every percentage increase in corrosion level there is about 1.6 and $1.8 \%$ decrease in loadcarrying capacity for experimental and numerical results, respectively. Numerical beam behaves stiffer compared to the experimental beam specimens. It is mainly because the numerical model beams are completely unhandled compared to experimental beam specimens. 


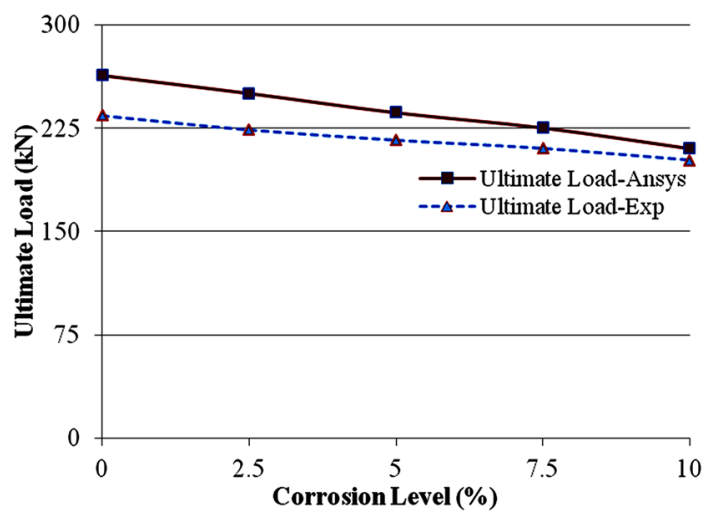

Fig. 11 Effect of corrosion on ultimate load-carrying capacity of beam specimen

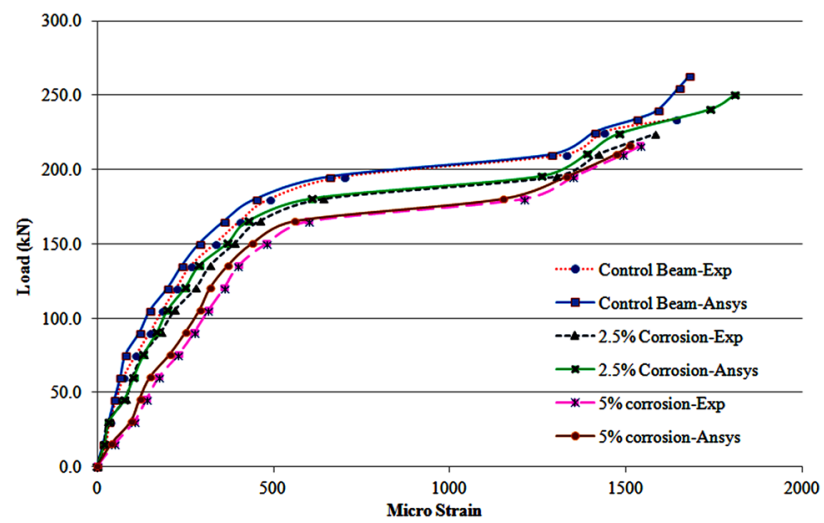

Fig. 12 Effect of different levels of corrosion on load strain behavior of beam specimen $(0,2.5$ and $5 \%)$

Load strain behavior for experimental beam and numerical model beam specimens is shown in Figs. 12 and 13 , respectively. It is observed that experimental beam shows higher strain values compared to the numerical model beam specimen. From Figs. 12 and 13, it is seen that as the load level increases strain value increases linearly in the initial stage. Then at higher corrosion levels, rate of increase of strain is higher for the same increment of load level compared to lower levels of corrosion. Control beam specimen performs better at increased corrosion levels. It is also observed that there is a sudden increase in strain values observed for the applied load interval, in all beam specimens. This indicates that there is a slip between reinforcement and surrounding concrete, since the corresponding strain value for yield strength of $25 \mathrm{~mm}$ diameter bar is much higher than the value of sudden increase in strain value. Slip at initiation indicates the point where flat portion begins and slip at end point where flat portion ends and strain values start continuing again. A view of strain contour is shown in Fig. 14.

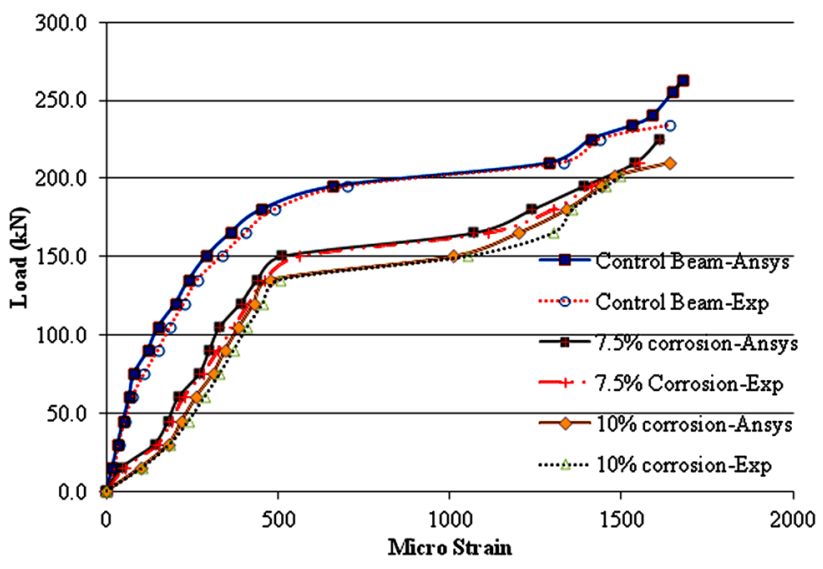

Fig. 13 Effect of different levels of corrosion on load strain behavior of beam specimen $(0,7.5$ and $10 \%)$

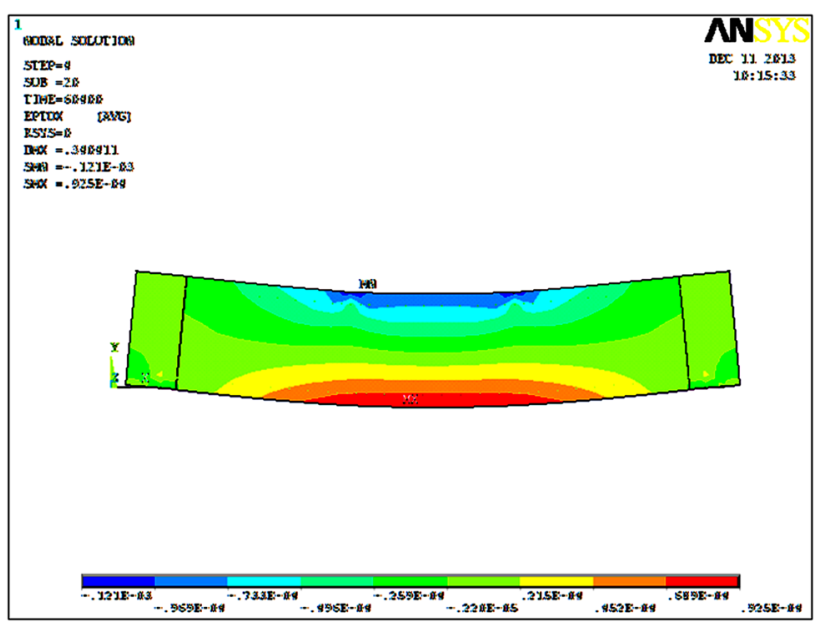

Fig. 14 A view of strain contour at control beam specimen

\section{Bar stress and bond stress performance of NBS beam}

Bond stress results for different levels of corrosions are obtained from Eq. (2). From Tables 1 and 2, it is observed that as the corrosion level increases bond stress value decreases. Poisson's effect is not considered in reduction of bar diameter. Percentage reduction in bond stress for different levels of corrosion, i.e., 2.5, 5, 7.5 and $10 \%$ with respect to control beam specimen is 6.6, 13.2, 21.6 and $29.4 \%$, respectively, for experimental concrete beam specimens and for numerical model it varies as 7.6, 15.8, 24.1 and $30.4 \%$, respectively.

From Figs. 15 and 16, it is exhibited that bond stress approximately drops for about $2.6 \%$ and $3 \%$ (at initiation of slip point) and also 2.1 and $2.4 \%$ (at end of slip point) for experimental and numerical model concrete beam specimens, respectively, for every percentage increase in corrosion level. 


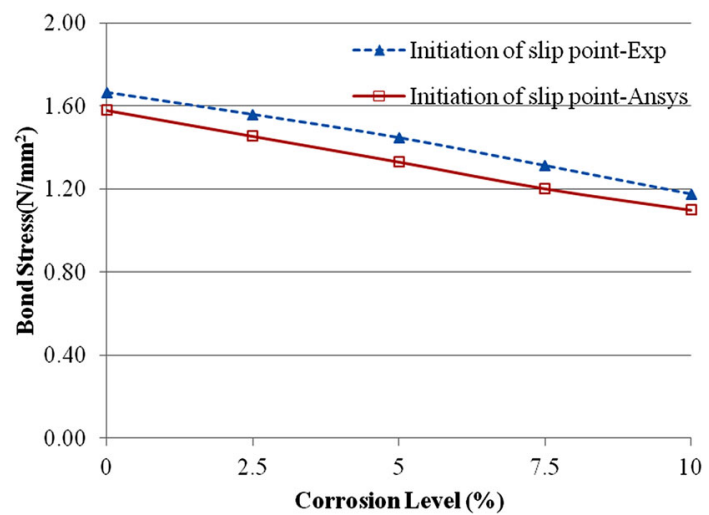

Fig. 15 Effect of corrosion levels on bond stress at initiation of slip values

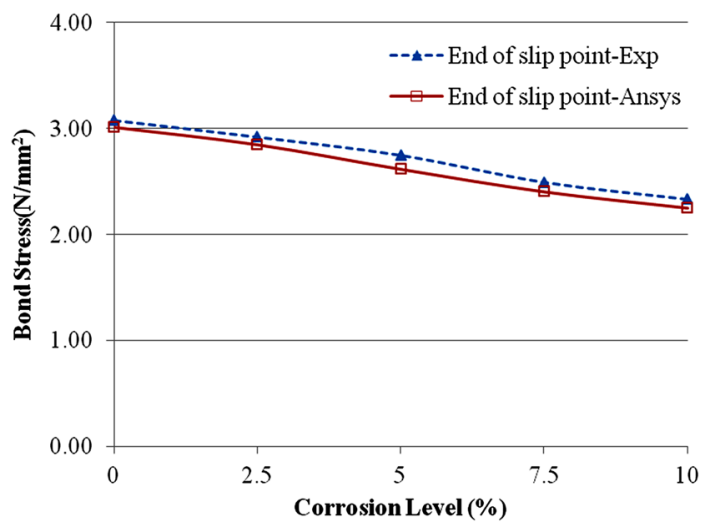

Fig. 16 Effect of corrosion levels on bond stress at end of slip values

Bond stress values for different degree of corrosion can be calculated from following equations obtained from Figs. 15 and 16, where $x$ is the corrosion level (\%) and $y$ the bond stress $\left(\mathrm{N} / \mathrm{mm}^{2}\right)$.

At initiation of slip point

(experimental) $y=-0.049 x+1.678 R^{2}=0.996$

(numerical) $y=-0.049 x+1.577 R^{2}=0.999$

At end of slip point

(experimental) $y=-0.076 x+3.099 R^{2}=0.992$

(numerical) $y=-0.078 x+3.019 R^{2}=0.996$

From the results, it is observed that numerical results show a variation less than $10 \%$ in load-carrying capacity and bond stress behavior compared to experimental results. Hence, proposed regression equation can be used for the determination of reduction in load-carrying capacity and bond stress behavior in the real-life structures subjected to different levels of corrosion.

\section{Conclusions}

Based on the comparison of experimental results to those obtained from analytical results, following remarks are drawn:

1. Experimental and numerical results show an variation less than $10 \%$ in load-carrying capacity, load deflection and bond stress behavior.

2. Reinforcement corrosion leads to the decline of loadcarrying capacity of NBS RC beam specimens. For every percentage increase in corrosion level, there is about 1.6 and $1.8 \%$ decrease in load-carrying capacity for experimental and numerical model beam specimen, respectively.

3. For increasing corrosion level, strain values increase in the initial stages. Then at higher corrosion levels, rate of increase of strain is higher for the same increment of load level, compared to the lower levels of corrosion.

4. Reinforcement corrosion causes degradation of the bond behavior. The strain value becomes large due to corrosion and the larger the corrosion lesser the bond stress value.

5. Percentage reduction in bond stress for different levels of corrosion, i.e., 2.5, 5, 7.5 and $10 \%$ with respect to control beam specimen was $6.59,13.17,21.56$ and $29.34 \%$, respectively, for experimental concrete beam specimens and for numerical analysis it varies as 7.6, 15.82, 24 and $30.4 \%$, respectively.

6. Bond stress approximately drops for about 2.6 and $3 \%$ (at initiation of slip point) and also 2.1 and $2.4 \%$ (at end of slip point) for experimental and numerical model concrete beam specimens, respectively, for every percentage increase in corrosion level.

7. Proposed regression equation is very much useful for quick assessment to predict the bond strength values for different corrosion levels in structures. Structures can be monitored for different corrosion levels using the applied corrosion monitoring instrument. Based on measured corrosion current density values, corrosion percentage can be determined. With the help of empirical prediction equation for different corrosion percentage, drop in load-carrying capacity as well as bond strength values can be determined.

Acknowledgments The partial financial support from Board of Research in Nuclear Sciences (BRNS) is gratefully acknowledged.

Conflict of interest The authors declare that they have no competing interests.

Authors' contributions Akshatha Shetty carried out the experimental and finite element modeling and proposed a prediction equation for the different levels of corrosion as a part of her research 
study, which is presented in the research work and drafted the manuscript. Katta Venkataramana and Babu Narayan K. S. have given their valuable suggestions and guidance, which played a distinct role in bringing this research work and paper to good shape. All authors read and approved the final manuscript.

Open Access This article is distributed under the terms of the Creative Commons Attribution 4.0 International License (http:// creativecommons.org/licenses/by/4.0/), which permits unrestricted use, distribution, and reproduction in any medium, provided you give appropriate credit to the original author(s) and the source, provide a link to the Creative Commons license, and indicate if changes were made.

\section{References}

Ahmad S (2009) Techniques for inducing accelerated corrosion of steel in concrete. Arabian J Sci Eng 34:95-104

Amleh L (2000) Bond deterioration of concrete. Ph.D. Thesis, Mc Gill University, Canada

ANSYS Commands Reference (2012) ANSYS Inc., http://www. ansys.com
Bhaskar S, Bharatkumar BH, Ravindra G, Neelamegam M (2010) Effect of corrosion on the bond behavior of OPC and PPC concrete. J Struct Eng 37:37-42

Fontana MG (2005) Corrosion engineering. New Delhi, Tata McGraw-Hill Education Private Limited

Goto Y (1971) Cracks formed in concrete around deformed tension bars. ACI J Proc 68:244-251

IS: 10262: recommended guidelines for concrete mix design, Bureau of Indian standards. New Delhi 2009

IS 456: Plain and reinforced concrete-Code of practice, Bureau of Indian Standards. New Delhi 2000

Paul RJ (1978) Top-bar and embedment length effects in reinforced concrete beams. Master Thesis, Department of Civil Engineering and Applied Mechanics, Mc Gill University Canada, pp 59-69

Pradhan B, Bhattacharjee B (2009) Performance evaluation of rebar in chloride contaminated concrete by corrosion rate. Constr Build Mater 23:2346-2356

Xu S (2003) The models of deterioration and durability evaluation of reinforced structure [D] Report. XI'an University of Architecture and Technology

Xiaoming Y, Hongqiang Z (2012) Finite element investigation on load carrying capacity of corroded RC beam based on BondSlip. Jordan J Civ Eng 6:134-146 